\title{
The demographic, clinical and forensic profile of offenders diagnosed with epilepsy referred to the Free State Psychiatric Complex Observation Unit in terms of section 77 and/or 78 of the Criminal Procedure Act 51 of 1977
}

P J Marais, MB ChB, MMed (Psych)

F J W Calitz, BA Hons, MA, DPhil

P J Pretorius, MB ChB, MMed (Psych)

Department of Psychiatry, Faculty of Health Sciences, University of the Free State, Bloemfontein

G Joubert, BA, MSC

Department of Biostatistics, Faculty of Health Sciences, University of the Free State

Limited information regarding the relationship between psychopathology associated with epilepsy, crime and the legal aspects thereof is available in South Africa.

Objectives. The demographic, clinical and forensic profile of alleged offenders diagnosed with epilepsy and referred to the Free State Psychiatric Complex Observation Unit from 2001 to 2006 was investigated.

Design. A retrospective cross-sectional study was conducted.

Results. Of the 69 alleged offenders aged $17-79$ years (median 30 years), 94.2\% were male, 81.2\% black, $72.5 \%$ single and $69.9 \%$ unemployed. The median level of education was grade 6 . Offences were violent in nature and committed against a person in $75 \%$ of cases. There was a direct link between epilepsy and the alleged offences in $7 \%$ of cases. Generalised epilepsy (34.8\%) and interictal psychosis (20.3\%) were the most commonly diagnosed conditions. Twenty-nine alleged offenders (42\%) lacked criminal responsibility and were not fit to stand trial. Most observati (79.2\%) diagnosed with generalised epilepsy were criminally liable and fit to stand trial. The highest rate of criminal incapacity was found among observati with interictal psychoses (85.7\%) and co-morbid mental retardation (90\%). Almost $60 \%$ of referred cases were declared as state patients by the court
Conclusion. In only $16 \%$ of cases, observati were found unaccountable because of epilepsy (automatisms) or postictal confusional states. Our findings confirmed an increased prevalence of violent behaviour during seizure-free periods. This contributes to the evidence that factors associated with epilepsy, rather than epilepsy itself, play an important role in the possible increased risk of violent behaviour in people with epilepsy.

Although violent behaviour may be associated with ictal, postictal and interictal phases ${ }^{14}$ of epilepsy, accounts of criminal behaviour directly linked to epilepsy remain rare and unconvincing. ${ }^{5}$ Modern studies generally fail to demonstrate an increased tendency towards violent behaviour in people with epilepsy. ${ }^{\circ}$ However, several epidemiological studies reveal an increased occurrence of violence among those with seizures compared with those without seizures. Research and clinical observations suggest that violence tends to occur more often during seizure-free periods, and that various factors contribute to aggressive behaviour associated with epilepsy. ${ }^{\circ}$ These are very complex and range from sociological to psychological and biological factors. Low socio-economic status, psychosocial consequences of epilepsy and the strong association between poor impulse control and structural brain pathology have all been linked to violence and epilepsy. ${ }^{4,7}$ Mendez et al. ${ }^{\circ}$ reported that violence associated with epilepsy usually results from associated factors such as poor impulse control, cognitive impairment, or other psychopathology.

While some authors such as Livingston ${ }^{8}$ view the relationship between epilepsy and violence as purely incidental, several other researchers have demonstrated an association. ${ }^{12,913}$ Many of the studies in this field, however, are methodologically flawed and fail to control for factors such as socio-economic status and the role of physical trauma. Whitman et al. ${ }^{14}$ concluded in their methodologically sound study that an intrinsic biological relationship between epilepsy and aggressiveness is unlikely. Their findings rather suggest a relationship between low socioeconomic status, epilepsy and violence. 
Behaviour during focal epileptic activity does not only depend on the brain region affected, but also on the mental content of the patient and other nonspecific factors at the time of onset of the seizure. ${ }^{15}$ Seizures affect cognitive function, behaviour and mental functioning and are associated with psychoses of various types and durations. 1.29 Patients with temporal lobe epilepsy (TLE) are particularly susceptible to more severe psychiatric illnesses. ${ }^{15}$ Personality changes associated with epilepsy are somewhat more controversial. ${ }^{1,2,9}$

South African law, like most Western legal systems, accepts that epileptic patients could commit unlawful acts as a result of an epileptic seizure. This is reflected in South African reported cases of R v. Schoonwinkel (1953), R v. Khumalo (1956) and $R$ v. Mkhize (1952). In the latter case, the accused acted in an epileptic automatism when he stabbed his sister to death with a carving knife he was using at the time. . $^{2,1618}$

Recommendations made by the Rumpff Commission in 1966 established epilepsy as a factor potentially influencing criminal responsibility. ${ }^{12,19}$ The requirements for the defence of mental illness together with a number of procedural matters are set out in chapter 13 of the Criminal Procedure Act 51 of 1977 ICPA 51 of 77). ${ }^{20}$ Among the requirements for the commission of an unlawful act is that the accused must have acted voluntarily. Automatism has come to denote in the criminal law 'conduct of which the doer is not conscious' and therefore not voluntary. In legal terms, a distinction is made between insane automatism, in which the state of unconsciousness proceeds from a disease of the mind lan internal factor), and sane automatism (due to an external factor such as a blow to the head)..$^{19}$ If successful, the defence of sane automatism leads to an unconditional acquittal of the accused, whereas insane automatism leads to committal of the person to a mental hospital. 8,1013,1619

Epileptic automatisms are regarded by the law as insane automatisms and therefore essentially as a defence of insanity. Paul et al., ${ }^{21}$ followed by Joubert et al., ${ }^{2}$ recommend a change in the law, as detention in psychiatric institutions is often inappropriate for patients with epilepsy. ${ }^{2.21}$ An amendment in 1998 to the CPA 51 of 1977 addressed this shortcoming and allows for some discretion in sentencing. ${ }^{22}$

The prevalence of epilepsy ranges from 4 to 13 per 1000 persons in various parts of the world. South Africa has a reported prevalence of 3.7 per 1000 of the general population, with a higher prevalence in blacks than in whites. ${ }^{2.23,24}$

A causal relationship between alleged criminal behaviour and an epileptic automatism is usually characterised by the following features: : 10,24,25 $^{2}$

- an undisputed history of epilepsy
- total amnesia regarding the events surrounding the alleged crime

- no or limited history of criminal behaviour

- eyewitness reports that the accused was confused and irrational at the time of the alleged crime

- murder, assault, theft and arson mostly committed by men

- sudden, open, random or unplanned actions at the time of the alleged crime

- strong remorse and guilt feelings about the incident

- absence of a motive associated with the crime

- no attempt to escape from the crime scene or to hide the crime, except when the person regains full consciousness and realises what he/she has done

- crimes are usually aimed against a person rather than property

- actions are often excessively violent, persistent and with an element of repetitive action.

In the South African context, research exploring the relationship between the cluster of psychopathologies associated with epilepsy, crime and the legal aspects thereof is lacking. Previous research mostly focused on epileptic automatisms. 2,8,1013 The courts and forensic psychiatrists are often faced with complex and controversial issues regarding epilepsy and criminal behaviour. The data from this research will demonstrate the influence of a diagnosis of epilepsy on forensic findings made at the Free State Psychiatric Complex (FSPC) Observation Unit in Bloemfontein. These data may increase our understanding of some of the controversies surrounding epilepsy and violence, and assist the legal system to deal with offenders diagnosed with epilepsy more appropriately.

The aim of the study was to investigate the role of epilepsy during the commitment of offences by offenders referred for 30-day psychiatric observation in terms of sections 77 and/or 78 of the Criminal Procedure Act 51 of 1977. The influence of epilepsy on accountability and triability was also investigated. A secondary objective was to establish whether offences were more likely to have been committed during ictal, postictal or interictal stages of epilepsy. Demographic data about the alleged offenders were also collected. All alleged offenders referred to the Observation Unit of the FSPC from 1 October 2001 to 30 September 2006 were included in the study.

\section{Methods \\ Definition of terms:}

- Section 77 (Triability) of the Criminal Procedure Act 51 of 1977 and amendment 1998 - the ability of the accused to understand court proceedings as to conduct a proper defence. ${ }^{19,22,26}$

- Section 78 (Accountability) of the Criminal Procedure Act 51 
of 1977 and amendment 1998 - the ability of the accused to appreciate the wrongfulness of his/her actions and whether he/she can act in accordance with an appreciation of the wrongfulness of his/her actions. . $92,226^{2}$

- Observati - refers to the alleged offenders being observed for a possible mental illness/defect during the 30-day observation period after being referred by the court in terms of section 77 and/or 78 of the Criminal Procedure Act. We are of the opinion that 'observati' accurately refers to a very specific population. It overlaps somewhat with the terms of 'accused' or 'alleged offenders' that are more generally used in this context. These three terms will be used interchangeably in this paper.

A retrospective cross-sectional study was conducted. The clinical records of 624 alleged offenders referred by the courts to the FSPC between 1 October 2001 and 30 September 2006 were screened for a possible clinical diagnosis of epilepsy. The Forensic Unit admission register as well as clinical records, psychiatric reports and nursing summaries compiled during the 30-day observation period were used to identify all possible cases of epilepsy. Sixty-nine (1 1 .1\%; 95\% confidence interval (Cl) $8.6-13.5 \%$ ) of the alleged offenders diagnosed with epilepsy were identified, and their data analysed for the purpose of this study.

Inclusion criteria used for the study were any one of the following:

- a positive medical history of epilepsy and/or treatment of epilepsy as obtained from the observati

- collateral information confirming epilepsy and/or current or previous treatment for epilepsy

- documented epileptic incidents or seizures during the 30-day observation period

- new cases of epilepsy diagnosed during the observation period.

Observati were excluded from the study in cases of:

- drug-related seizures, or seizures related to transient changes in cerebral function (except epilepsy)

- conversion disorder with seizures. ${ }^{1,27}$

Electro-encephalograph (EEG) results were not available for all observati, as the need for EEGs had been determined by the clinicians during the observation period before commencement of the study. An abnormal EEG was therefore not regarded as one of the criteria for inclusion in the study.

Psychiatric observations had been completed in terms of sections 77 and/or 78 of the Criminal Procedure Act 51 of 1977, before the onset of the study. The clinical notes and reports of all members of the multiprofessional team as well as the records of the final multiprofessional team meetings were scrutinised for positive study entry criteria. Copies of the psychiatric reports submitted to the court were also scrutinised for a diagnosis of epilepsy as well as findings on triability and accountability.

Observati had undergone several assessments of their physical and mental status during the period of observation. Evaluations had been conducted individually and in group settings by members of the multiprofessional team by means of repeated psychiatric interviews, psychometric tests, a physical examination, special investigations, a psychosocial report and review of the facts of the case. The team included at least one psychiatrist, a psychiatric registrar, a social worker, clinical psychologists, psychiatric professional nurses and an occupational therapist.

A computerised data form was compiled and used to enter the relevant information from the clinical files of the study population. The researchers themselves completed the data forms from the content of the clinical files of the accused.

A pilot study was conducted on 10 clinical files of alleged offenders referred for observation during the period 1 January 2000 - 30 September 2001.

Analysis of the data was done by the Department of Biostatistics, University of the Free State. The data were summarised by frequencies and percentages (categorical variables), and means or percentiles (numerical variables), while $95 \% \mathrm{Cl}$ was calculated for the main outcome. Associations were determined using contingency tables with chi-square tests.

The study was approved by the Ethics Committee, Faculty of Health Sciences of the University of the Free State, as well as the Clinical Ethics and Research Committee of the FSPC. Amendments to the data form resulting from the pilot study were also approved by these committees.

\section{Results and discussion}

Sixty-nine observati were included in the study. Most of the participants were male (94.2\%) and single (72.5\%), with ages ranging from 17 to 79 years (median 30 years). The majority were black (81.2\%), while $11.6 \%$ were white and $7.3 \%$ coloured. More than half $(59.4 \%)$ of the offenders with a diagnosis of epilepsy were declared as state patients by the courts.

Nine per cent had no school education. The highest level of education was primary school education in $56.1 \%$ and secondary school education in $33.3 \%$, while only $1.5 \%$ had tertiary education. The median level of education was grade 6 , and $7.6 \%$ had passed grade 12 .

Most offenders (69.9\%) were unemployed at the time of the alleged crime, and $14.5 \%$ were known psychiatric patients 
receiving disability grants. Approximately $4 \%$ were self-employed and $2.9 \%$ were pensioners at the time of the alleged crime. The study population had a significantly higher unemployment rate $(69.9 \%)$ than the general population $(41.6 \%){ }^{28}$

The majority of offenders (95.7\%) were referred according to both sections 77 and 78 of the CPA. Some observati were simultaneously charged with more than one offence. More offences were committed against a person (75\%) than property (25\%). Other offences (10.5\%) included failure to pay maintenance, indecent assault and reckless driving. The three most common offences committed against a person (Table I) were rape, murder and assault, while malicious damage to property and theft were the two most common offences committed against property. Crimes committed by the study population tended to be violent in nature. These findings are consistent with those of other researchers. ${ }^{2,12,16,25}$ The data in Table II show the offences committed against property.

Of particular concern was the fact that approximately half (49\%) of the alleged offenders had a previous criminal record. Study participants in this subgroup mostly fitted into the diagnostic categories of generalised epilepsy (34.5\%) and interictal psychoses $(27.6 \%)$.

Substance abuse, especially alcohol and cannabis, was reported by a substantial number of defendants as a lifetime problem. Results with regard to substance abuse are shown in Table III. Seventeen per cent of offenders were reported to be under the influence of alcohol and $11.6 \%$ under the influence of cannabis at the time of the alleged crime. Methaqualone (1.5\%) and cocaine use (1.5\%) were less commonly involved. These findings support the direct link between drug abuse, low socio-economic status and crime, as reported in previous studies. ${ }^{29,30}$

Approximately half of the offenders had a history of head injury associated with loss of consciousness, while abnormal EEGs and computed tomography (CT) brain scans were found in a considerable number of observati referred to undergo these investigations. These findings are summarised in Table III.

A clinical diagnosis of epilepsy was confirmed by a positive medical history or collateral information in $92.8 \%$ and $92.6 \%$ of cases, respectively. Approximately one-third (30.4\%) of defendants had a generalised seizure documented during the 30-day observation period. A new diagnosis of epilepsy was made during the observation period in $10.1 \%$ of the study population.

Eyewitness reports confirmed occurrence of an epileptic seizure on the day of the alleged crime in $17.4 \%$ of cases. Sudden unexpected onset of a confused mental state accompanied by irrational behaviour was confirmed by eyewitness reports in $30.4 \%$ of cases, with similar episodes re-occurring in $36.2 \%$ of cases during the observation period.

The most frequently diagnosed disorders and co-morbid conditions recorded at the end of the observation period are set out in Table IV. These included generalised epilepsy (34.8\%), interictal psychosis (20.3\%), generalised epilepsy with mental retardation (14.5\%), and postictal psychiatric disorders (1 1.6\%).

Table I. Offences committed against a person

\begin{tabular}{lcc} 
Table l. Offences committed against a person & \\
\hline & & $\%$ \\
\hline Offence & No. of offences (N=57) & 26.3 \\
\hline Rape & 15 & 24.6 \\
Murder & 14 & 19.3 \\
Assault & 11.0 & 7.0 \\
Attempted murder & 4 & 5.3 \\
Attempted rape & 3 & 10.5 \\
Assault with intent to cause grievous bodily harm & 6 & 3 \\
Other & & \\
\end{tabular}

Table II. Offences committed against property

\begin{tabular}{lcc}
\hline Offence & No. of offences (N=19) & $\%$ \\
\hline Malicious damage to property & 8 & 42.1 \\
Theft & 5 & 26.3 \\
Housebreaking & 2 & 10.5 \\
Motor vehicle theft & 2 & 10.5 \\
Arson & 1 & 5.3 \\
Other & 1 & 5.3 \\
\hline
\end{tabular}




\begin{tabular}{|c|c|c|}
\hline & Frequency & $\%$ \\
\hline \multicolumn{3}{|l|}{ Substance abuse $(N=69)$} \\
\hline Alcohol & 42 & 60.9 \\
\hline Cannabis & 26 & 37.7 \\
\hline Methaqualone & 2 & 2.9 \\
\hline \multicolumn{3}{|l|}{ Neurological co-morbidity* } \\
\hline Previous head injury with unconsciousness $(N=69)$ & 33 & 47.8 \\
\hline Abnormal EEG $(N=44)$ & 21 & 47.7 \\
\hline Abnormal CT brain ( $N=42)$ & 20 & 47.6 \\
\hline
\end{tabular}

\section{Table IV. Epilepsy-related diagnostic categories}

\begin{tabular}{lcc}
\hline Diagnostic categories & Frequency (N=69) & $\%$ \\
\hline Generalised epilepsy & 24 & 34.8 \\
Interictal psychoses (psychotic disorder due to general medical condition, epilepsy) & 14 & 20.3 \\
Generalised epilepsy and mental retardation & 10 & 14.5 \\
Postictal psychiatric disorders & 5 & 11.6 \\
Psychiatric disorders associated with ictal phase (temporal lobe epilepsy) & 4.2 & 4.8 \\
Generalised epilepsy and head injury & 4 & 5.8 \\
Generalised epilepsy and substance abuse & & \\
\hline
\end{tabular}

The findings in terms of sections 77/78 of the CPA 51 of 1977 are summarised in Table $V$. The majority (42\%) of offenders with epilepsy were neither fit to stand trial nor accountable. Twenty-one observati (30.4\%) were both fit to stand trial and accountable, while $10(14.5 \%)$ were fit to stand trial but not accountable.

The association between the clinical categories and findings in terms of sections 77/78 of the CPA 51 of 1977 are summarised in Table VI. Type of epilepsy was significantly associated with triability and accountability. Most (79.2\%) observati diagnosed with generalised epilepsy (24) were fit to stand trial and accountable. In contrast, alleged offenders with interictal psychoses (14) or generalised epilepsy with co-morbid mental retardation (10) were mostly $(85.7 \%$ and $90 \%$, respectively) not fit to stand trial and unaccountable $(p<0.05)$. A direct relationship between the alleged offence and postictal behaviour was found in $62 \%$ of offenders with reported postictal disorders, who were therefore unaccountable. Four offenders diagnosed with TLE (i.e. $80 \%$ of this subgroup) were found to be unaccountable, indicating a direct relationship between the seizure and the alleged offence.

\section{Conclusion}

Eleven per cent $(95 \% \mathrm{Cl} 8.6$ - 13.5\%) of all the referred alleged offenders were diagnosed with epilepsy and included in the study. Approximately half (49\%) of the observati diagnosed with epilepsy had a previous criminal record. Eighty per cent (4) of alleged offenders diagnosed with TLE were unaccountable but triable. Those with generalised epilepsy were fit to stand trial and accountable in $79.2 \%$ of cases. Only $41.4 \%$ of offenders with interictal psychosis and $34.5 \%$ of offenders with epilepsy with co-morbid mental retardation were fit to stand trial and unaccountable. The majority (59.4\%) of the patients in the study were declared by the courts as state patients. Forty-two per cent (29) of the study population was neither accountable nor fit to stand trial.

Eighteen (26\%) offenders with generalised epilepsy had a final co-morbid diagnosis (mental retardation (10), head injury (4) or substance abuse (4)I. A large percentage (72.2\%) of this group was neither fit to stand trial nor accountable. Although $47 \%$ of observati had a history of loss of consciousness requiring hospitalisation after a head injury, this was only reflected in the final diagnosis of 4 cases.

Ictal and postictal disorders were directly associated with the alleged offences in 16\% of observati diagnosed with epilepsy. This supports the fact that other biological and psychosocial factors are important contributors to behavioural abnormalities in patients with epilepsy. Factors such as mental retardation, a history of head injury, unemployment and substance abuse were all major contributing factors in our study population. 


\begin{tabular}{lrr} 
Table V. Findings in terms of sections $\mathbf{7 7}$ and/or $\mathbf{7 8}$ of the Criminal Procedure Act $\mathbf{5 1}$ of 1977 & Frequency (N=69) & $\%$ \\
\hline Findings & 29 & 42.0 \\
\hline Unaccountable and not triable & 21 & 30.4 \\
Accountable and triable & 10 & 14.5 \\
Unaccountable but triable & 5 & 2.2 \\
Diminished accountability and triable & 1 & 2.9 \\
Accountable but not triable & 1 & 1.4 \\
Unaccountable & 1.4 \\
Diminished accountability and not triable & & \\
\hline
\end{tabular}

\begin{tabular}{|c|c|c|c|c|c|c|c|}
\hline \multirow[b]{2}{*}{ Diagnostic categories } & \multicolumn{7}{|c|}{ Findings in terms of sections 77 and/or 78*: frequency (N (\%)) } \\
\hline & UA NT & A T & UA T & $\operatorname{Dim} A T$ & A NT & UA & Dim A NT \\
\hline Generalised epilepsy ( $N=24)$ & $2(8.3)$ & $19(79.2)$ & - & $2(8.3)$ & - & - & $1(4.2)$ \\
\hline \multirow{2}{*}{$\begin{array}{l}\text { Interictal psychosis }(N=14) \\
\text { Generalised epilepsy and mental retardation } \\
(N=10)\end{array}$} & $12(85.7)$ & - & $2(14.3)$ & - & - & - & - \\
\hline & $9(90)$ & - & - & - & $1(10)$ & - & - \\
\hline Postictal psychiatric disorder $(N=8)$ & $2(25)$ & - & $5(62.5)$ & - & $1(12.5)$ & - & - \\
\hline $\begin{array}{l}\text { Ictal-related psychiatric disorders, temporal lobe } \\
\text { epilepsy }(N=5)\end{array}$ & - & - & $3(60)$ & $1(20)$ & - & $1(20)$ & - \\
\hline Generalised epilepsy and head injury ( $N=4)$ & $2(50)$ & - & - & $2(50)$ & - & - & - \\
\hline Generalised epilepsy and substance abuse $(N=4)$ & $2(50)$ & $2(50)$ & - & - & - & - & - \\
\hline \multicolumn{8}{|c|}{$\begin{array}{l}\text { *Findings in terms of sections } 77 \text { and/or } 78 \text { : UA NT }=\text { unaccountable and not triable } A T=\text { accountable and triable UA } T=\text { unaccountable but triable } \\
\text { Dim A T = diminished accountability and triable A NT = accountable but not triable UA = unaccountable Dim A NT }=\text { diminished accountability } \\
\text { and not triable. }\end{array}$} \\
\hline
\end{tabular}

Surprisingly, only 8 observati with postictal-related psychiatric disorders were referred by the court. A possible explanation for this finding may be that these cases were identified as having epilepsy and appropriately channelled through the medical rather than the legal system, which may result from a frequently observable link between postictal abnormal behaviour and generalised seizures.

The study was not designed to investigate the complex interaction of various aspects such as unemployment, poverty, structural brain damage, epilepsy and violent behaviour. Although no final conclusion pertaining to possible risk factors predicting future criminal behaviour was made, our study population seemed to have a disparately high percentage of previous criminal charges, history of substance abuse and previous head injury.

Limitations of this study include the fact that only offenders referred to the Observation Unit at the FSPC were included in the study. Another limitation is that cases of epilepsy could have been missed during the observation period or the court procedures. It is possible that cases of non-convulsive epileptic seizures were missed by the courts as well as during psychiatric evaluation. Furthermore, owing to financial restrictions EEGs and CT brain scans were not performed on all observati. It is possible that the courts did not refer cases where, in their opinion, it was clear that no link between epilepsy and the alleged crime existed.

Academic research in the field of forensic psychiatry has been largely neglected in South Africa. We trust that information generated from this research has shed some light on the demographic, clinical and forensic profile of offenders in criminal cases who have been diagnosed with epilepsy. However, further studies specifically designed to investigate the complex interactions of various factors involved in the possible association between violence and epilepsy need to be conducted.

We are confident that the information gathered from this study will sensitise the courts to the possible influence of epilepsy on offenders' fitness to stand trial and accountability. It is therefore of the utmost importance that courts should obtain expert opinion in these cases.

Daleen Struwig, medical writer, Faculty of Health Sciences, University of the Free State, is acknowledged for technical and editorial preparation of the manuscript for publication. 


\section{References}

1. Lishman WA. Organic Psychiatry. 3rd ed. Oxford: Blackwell Scientific Publications, 1997: 237-314.

2. Joubert AF, Van Rensburg PHIJ, Gagiano CA, Verschoor T. Epilepsy in forensic psychiarry. Eur Neuropsychopharmacol 1996;6(suppl 3):15.

3. Bolwig TG. Classification of psychiatric disturbances in epilepsy. In: Trimble MR, Bolwig TG, eds. Aspects of Epilepsy and Psychiatry. London: John Wiley \& Sons, 1986: 1-8.

4. Van Rensburg PHI, Gagiano CA, Verschoor T. Possible reasons why certain epileptics may commit an unlawful act during or directly after a seizure. Med Law $1994 ; 13: 373-379$

5. Borum R, Appelbaum KL. Epilepsy, aggression, and criminal responsibility. Psychiatr Serv 1996;47:762-763

6. Mendez MF. Postictal violence and epilepsy. Psychosomatics 1998;35:478-480

7. Fenwick P. Aggression and epilepsy. In: Reynolds EH, Trimble MR, eds. Epilepsy and Psychiatry. New York: Churchill Livingstone, 1981: $31-60$

8. Livingston S. Epilepsy and murder. JAMA 1964;188:172

9. Wolf P. Use of antiepileptic drugs in epileptology with respect to psychiatry. Neuropsychobiology 1993;27:127-131.

10. Gunn J, Fenton G. Epilepsy, automatism, and crime. Lancet 1971;1:1 173-1 176.

11. Lewis DO, Pincus JH, Shanok SS, Glaser GH. Psychomotor epilepsy and violence in a group of incarcerated adolescent boys. Am J Psychiatry 1982;139:882-887.

12. Van Rensburg PHJ. Die verband tussen epilepsie en strafregtelike toerekenbaarheid [The relationship between epilepsy and criminal accountability]. Doctoral thesis, University of the Free State, Bloemfontein, 1987.

13. Cope RV, Donovan WM. A case of insane automatism? Br J Psychiatry 1979;35:574-575

14. Whitman S, Coleman TE, Patmon C, Desai BT, Cohen R, King L. Epilepsy in prison: elevated prevalence and no relationship to violence. Neurology 1984;34:775-782.

15. Trimble MR. Psychiatric aspect of epilepsy. Psychiatric Developments 1987:5:285-
16. Fenwick PB. Automatism, medicine and the law. Psychological Medicine Monograph Supplement 1990; 17:1-27

17. Van Jaarsveldt CJR, Van Rensburg PHIJ, Verschoor T, Meyer CJ. Epileptiese outomatisme: 'n gevallestudie [Epileptic automatism: a case study]. Geneeskunde $1991 ; 33: 15-21$.

18. Fenwick PB. Automatism: In: Bluglass R, Bowden P, eds. Principles and Practice of Forensic Psychiatry. London: Churchill Livingstone, 1990

19. Snyman CR. Criminal Law. 4th ed. Durban: LexisNexis Butterworths, 2002: 143 248.

20. Juta Legislation Service. Criminal Procedure Act 51 of 1977. Cape Town: Juta Legal and Academic Publishers, 1985

21. Paul GM, Lange KW. Epilepsy and criminal law. Med Sci Law 1992;32:160-166.

22. Kaliski S. Psycholegal Assessment in South Africa. Cape Town: Oxford University Press, 2006: 95-11

23. Van Rensburg PHJJ, Gagiano CA, Verschoor T. Die voorkoms van epilepsie [The prevalence of epilepsy]. Psychiatric Insight 1989;6:4-7

24. Osuntokun BO. Epilepsy in Africa: epidemiology of epilepsy in developing countries in Africa. Tropical and Geographical Medicine 1978;30:23-32.

25. Milne HB. Epileptic homicide: drug-induced. Br J Psychiatry 1979; 134:547-548

26. Kriegler J, Hiemstra VG. Suid-Afrikaanse Strafproses [South African Criminal Procedure]. 6th ed. Durban: Butterworths, 2002: 202-230

27. Liske E, Foster FM. Pseudoseizures: a problem in the diagnosis and the managemen of epileptic patients. Neurology 1964;14:41-49.

28. Statistics South Africa. Census 2001. http://www.statssa.gov.za/ censusO 1/html/ CinBrief/CIB2001.pdf (accessed 10 November 2008)

29. Parry CD, Plüdddeman A, Louw A, Leggett T. The 3-metros study of drugs and crime in South Africa: findings and policy implications. Am J Drug Alcohol Abuse 2004; $30: 167-185$

30. Bennett, Holloway K. The association between multiple drug misuse and crime. J Offender Ther Comp Criminol 2005:49:63-81. 